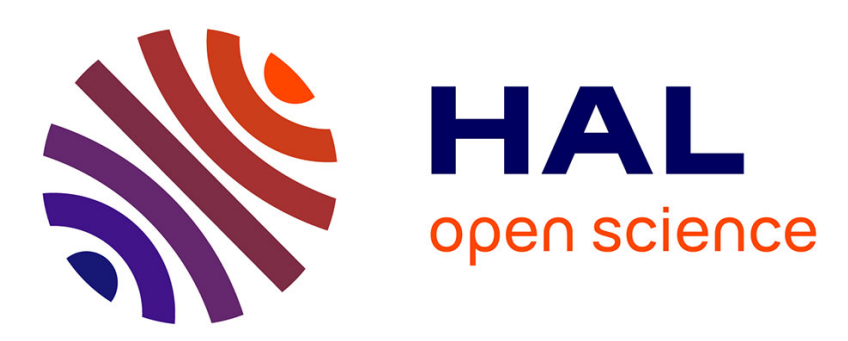

\title{
Formation of nanosized hills on Ti3SiC2 oxide layer irradiated with swift heavy ions
}

Jean-Christophe Nappé, Isabelle Monnet, F. Audubert, Philippe Grosseau, Michel Beauvy, Mourad Benabdesselam

\section{- To cite this version:}

Jean-Christophe Nappé, Isabelle Monnet, F. Audubert, Philippe Grosseau, Michel Beauvy, et al.. Formation of nanosized hills on $\mathrm{Ti} 3 \mathrm{SiC} 2$ oxide layer irradiated with swift heavy ions. Nuclear Instruments and Methods in Physics Research Section B: Beam Interactions with Materials and Atoms, 2012, 270 (1), pp.36-43. 10.1016/j.nimb.2011.09.027, . hal-00664404

\section{HAL Id: hal-00664404 https://hal.science/hal-00664404}

Submitted on 4 May 2013

HAL is a multi-disciplinary open access archive for the deposit and dissemination of scientific research documents, whether they are published or not. The documents may come from teaching and research institutions in France or abroad, or from public or private research centers.
L'archive ouverte pluridisciplinaire HAL, est destinée au dépôt et à la diffusion de documents scientifiques de niveau recherche, publiés ou non, émanant des établissements d'enseignement et de recherche français ou étrangers, des laboratoires publics ou privés. 


\title{
Formation of nanosized hills on $\mathrm{Ti}_{3} \mathrm{SiC}_{2}$ oxide layer irradiated with swift heavy ions
}

\section{Authors}

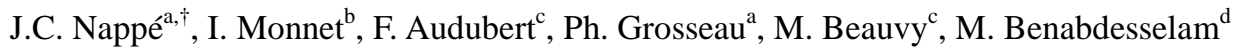 \\ ${ }^{a}$ École Nationale Supérieure des Mines, SPIN/PMMC, LPMG UMR CNRS 5148, 158 cours Fauriel, 42023 Saint- \\ Étienne cedex 2, France \\ ${ }^{\mathrm{b}}$ CIMAP, CEA-CNRS-ENSICAEN-Université de Caen Basse Normandie, Bd Henri Becquerel, BP 5133, F-14070 \\ Caen cedex 5, France \\ ${ }^{\mathrm{c}}$ CEA, DEN, DEC/SPUA/LTEC, Cadarache, 13108 St Paul lez Durance, France \\ ${ }^{\mathrm{d}}$ Université de Nice - Sophia Antipolis, LPMC UMR CNRS 6622, Parc Valrose, 06108 Nice cedex 2, France
}

\begin{abstract}
In the framework of the Generation IV International Forum, carbides are sensed for the design of the fuel cladding of the Gas-cooled Fast Reactor. Among the studied carbides, $\mathrm{Ti}_{3} \mathrm{SiC}_{2}$ has the advantage of combining the properties of both metals and ceramics. After performing irradiations with $92 \mathrm{MeV}$ Xe ions to $10^{19} \mathrm{~m}^{-2}$, hills were observed by AFM on the surface of $\mathrm{Ti}_{3} \mathrm{SiC}_{2}$. Such topographic modification seems to have never been observed in other materials irradiated in such conditions. A characterization of these hills by both XPS and X-TEM highlighted that these surface modifications do not appear in $\mathrm{Ti}_{3} \mathrm{SiC}_{2}$ but in a native amorphous oxide layer on the sample. Moreover, the thickness of this oxide layer grows under irradiation. The comparison between different irradiations permitted to conclude that this surface modification is due to electronic interactions in this amorphous layer, and a threshold in electronic stopping power for hill formation is evidenced.
\end{abstract}

Keywords: $\mathrm{Ti}_{3} \mathrm{SiC}_{2}$, heavy ion irradiation, oxidation, atomic force microscopy, cross-sectional transmission electron microscopy, X-ray photoelectron spectrometry

PACS: 81.05.Je, 61.80.Lj, 25.75.Ag, 34.50.Bw, 28.41.Bm, 81.65.Mq, 68.37.Ps, 68.37.Og, 79.60.-i

\section{Introduction}

The Gas-cooled Fast Reactor (GFR) is one of the six nuclear systems currently studied in the framework of the Generation IV International Forum (GIF) [1]. Because of working conditions planned for this reactor - high helium pressure, and high temperature (around $1000{ }^{\circ} \mathrm{C}$ in nominal operating conditions, and up to $1600-2000{ }^{\circ} \mathrm{C}$ in accidental scenario), refractory materials are required for the design of the fuel cladding. That is why many studies are conducted on carbides, as well for their development and the improvement of their properties [2-4], as to understand their behaviour under irradiation [5-8].

Among the studied carbides, the so-called MAX phase $\mathrm{Ti}_{3} \mathrm{SiC}_{2}$ seems to offer excellent prospects [9,10]. Indeed, in addition to presenting some resistance to mechanical stresses [11-14], which includes a better tenacity than the majority of carbides $\left(\mathrm{K}_{1 \mathrm{C}} \approx 9 \mathrm{MPa} \mathrm{m}^{1 / 2}[9,15]\right)$, its nanolamellar structure could be useful in the conception of the cladding, for instance, using it as interphase in ceramic matrix composite. Moreover, this material with behaviour at the frontier between ceramics and metals, presents thermal properties fitting all the specifications required for this cladding: its decomposition temperature varies in the literature between 1400 and $1700{ }^{\circ} \mathrm{C}[11,16,17]$, it is thermal shock resistant [10,16], and presents a thermal conductivity above $30 \mathrm{~W} \mathrm{~m}^{-1} \mathrm{~K}^{-1}$ at the nominal working temperature of GFR [17]. However, to date few studies have been conducted on $\mathrm{Ti}_{3} \mathrm{SiC}_{2}$ behaviour under irradiation [18-21].

Previously, it was shown that $\mathrm{Ti}_{3} \mathrm{SiC}_{2}$ material exhibits some hills on its surface after an irradiation at room temperature with $92 \mathrm{MeV}$ Xe ions to a fluence higher than $5 \times 10^{18} \mathrm{~m}^{-2}$ [22]. This kind of relief looks like ripple formation under low energy ion irradiation in several materials, but was never observed for such irradiation parameters (swift heavy ion at normal incidence, in this range of fluence).

The aim of this study is hence to better characterize both the formation and the composition of these hills, to suggest an hypothesis about their origin. In order to confirm that this surface structuration is due to electronic excitations, two kind of irradiation were performed: some with swift heavy ions for which the energy loss is essentially due to electronic interactions, and some with lower energy ions for which the nuclear interaction is the most important energy loss process.

$\dagger \quad$ Corresponding author. Tel.: +33 477420 213; fax: +33 477499694 .

E-mail address: jc.nappe@yahoo.fr (JC. Nappé). 


\section{Experimental}

The studied material is a polycrystalline $\mathrm{Ti}_{3} \mathrm{SiC}_{2}$ (3-ONE-2, Vorhees, NJ, USA). X-ray diffraction (XRD) measurements yielded $19 \%$ of $\mathrm{TiC}_{0.92}$ and $7 \%$ of $\mathrm{TiSi}_{2}$. The samples provided in the form of plates are cut into $10 \times 5 \times 5 \mathrm{~mm}^{3}$ samples and polished with diamond paste of a size down to $1 \mu \mathrm{m}$.

Swift heavy ion irradiations were performed at room temperature with $74 \mathrm{MeV} \mathrm{Kr}$ and $92 \mathrm{MeV}$ Xe ions provided by the IRRSUD beamline of GANIL (Caen, France). Low energy irradiations were carried out at room temperature with $4 \mathrm{MeV}$ Au ions provided by the ARAMIS accelerator of CSNSM (Orsay, France). All the irradiation conditions are summarized in Table 1.

Table 1: Irradiations carried out in this study. Sn and Se stand respectively for nuclear and electronic stopping power; they are estimated on the surface of $\mathrm{Ti}_{3} \mathrm{SiC}_{2}$ with the TRIM-2008 code [23].

\begin{tabular}{lcccc}
\hline \multirow{2}{*}{ Beam line } & Ion & Stopping power $\left(\mathrm{keV} \mathrm{nm}^{-1}\right)$ & \\
& & $\mathrm{Sn}$ & $\mathrm{Se}$ & \\
\hline ARAMIS & $4 \mathrm{MeV} \mathrm{Au}$ & 1.1 & 4.00 & $10^{16}, 10^{17}, 10^{18}, 10^{19}$ \\
\hline & $74 \mathrm{MeV} \mathrm{Kr}$ & $5.5 \times 10^{-2}$ & 15.7 & $10^{16}, 10^{17}, 10^{18}, 10^{19}$ \\
\cline { 2 - 5 } IRRSUD & $92 \mathrm{MeV} \mathrm{Xe}$ & $5.1 \times 10^{-2}$ & 21.5 & $\begin{array}{c}10^{16}, 10^{17}, 2 \times 10^{17}, 4 \times 10^{17}, 8 \times 10^{17}, 10^{18}, \\
2 \times 10^{18}, 4 \times 10^{18}, 8 \times 10^{18}, 10^{19}, 1.3 \times 10^{19}\end{array}$ \\
& & & 2
\end{tabular}

Three techniques were used to characterize the surface, before and after irradiation: atomic force microscopy (AFM), cross-sectional transmission electron microscopy (X-TEM), and X-ray photoelectron spectrometry (XPS). AFM was performed in contact mode (Veeco Nanoscope III A) with a $\mathrm{Si}_{3} \mathrm{~N}_{4}$ tip of $0.12 \mathrm{~N} \mathrm{~m}^{-1}$ in stiffness. The transmission electron microscope, equipped with a field-emission gun, worked at $200 \mathrm{kV}$ (Jeol 2010F). To examine the change in composition caused by irradiation, scanning energy dispersive spectrometry (STEM/EDS) was used: it permits to have qualitative information on chemical composition. The spot size used was $0.7 \mathrm{~nm}$.

A Thermo VG Thetaprobe XPS with a aluminum K $\alpha$ source was used to analyze the surface chemistry. Analyzes were performed in constant energy resolution mode with a passage energy of $50 \mathrm{eV}$. Spectral decomposition was achieved thanks to CasaXPS software [24], using the Shirley's method [25] to define the baseline, and a pseudo-Voigt function of Lorent'z factor equals to 0.3 to describe the peaks.

\section{Results}

No hill is noticed on the as-polished specimen, hereafter called pristine sample [22]. After irradiation with $92 \mathrm{MeV} \mathrm{Xe}$ ions, to a fluence of $10^{19} \mathrm{~m}^{-2}$, surface modifications of $\mathrm{Ti}_{3} \mathrm{SiC}_{2}$ phases is evidenced by AFM observations (Figure 1). In $\mathrm{TiC}$, such modifications are also evidenced, but the hills are smaller. There is no visible modification in TiSi ${ }_{2}$. X-TEM observations and XPS analysis were performed in this sample and in the pristine one in order to better characterize the hills on the $\mathrm{Ti}_{3} \mathrm{SiC}_{2}$ surface. 

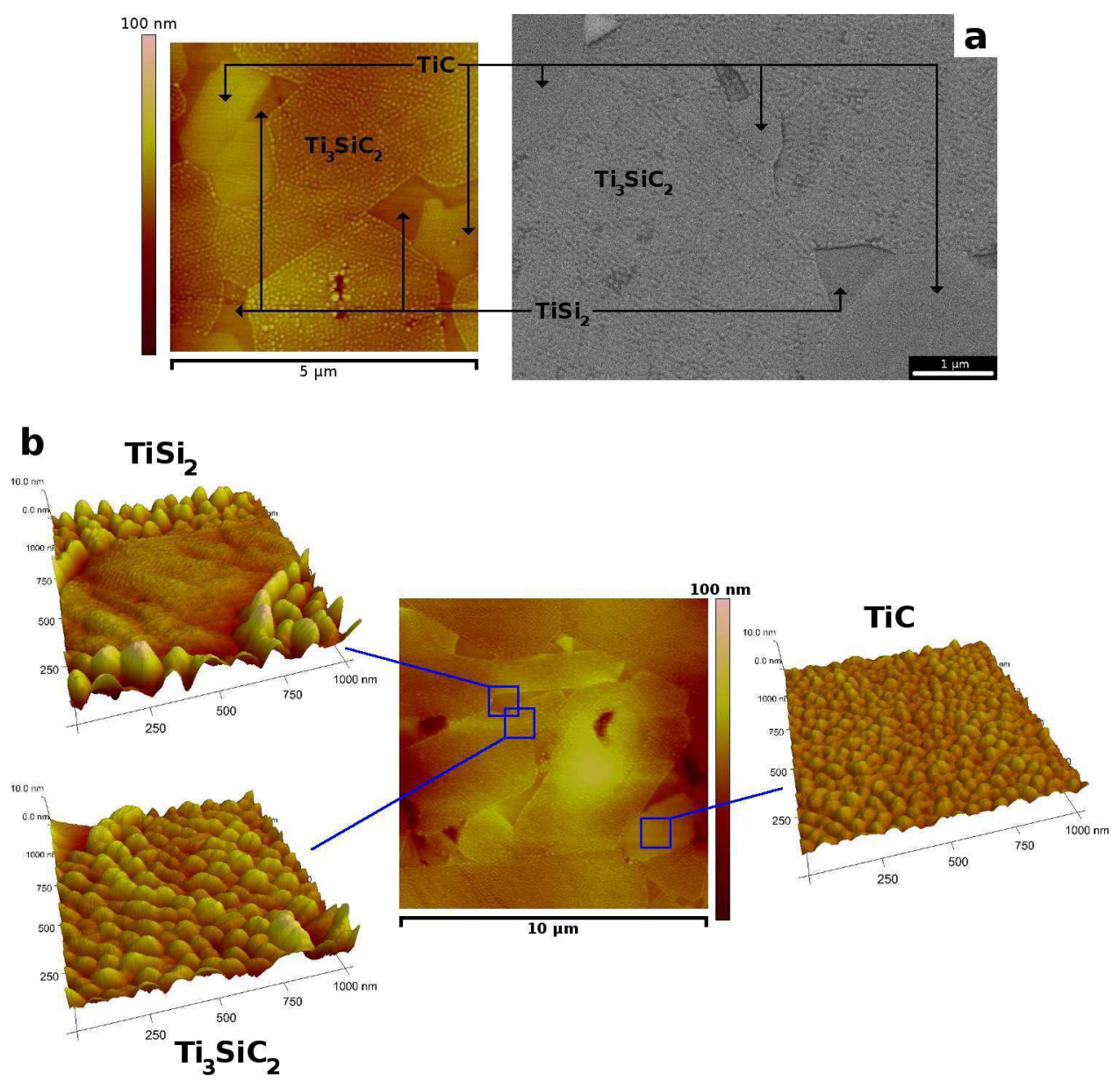

Figure 1: Observation by AFM and scanning electron microscopy of the microstructure of the sample irradiated at room temperature with $92 \mathrm{MeV}$ Xe ions to $10^{19} \mathrm{~m}^{-2}$ : (a) phase identification using energy dispersive X-ray spectrometry, (b) hills are observable on both $\mathrm{Ti}_{3} \mathrm{SiC}_{2}$ and $\mathrm{TiC}$ grains, but not on $\mathrm{TiSi}_{2}$ ones.

In the pristine sample, a surface layer may actually be noticed by X-TEM (Figure 2). This layer appears to be uniform on the surface: its thickness was estimated to $3 \mathrm{~nm}$. Observation in high resolution mode under many inclinations of the sample, even in axis zone for the underneath matrix, reveals that this layer is amorphous. EDS indicates that this layer seems to contain more oxygen than the underneath material.

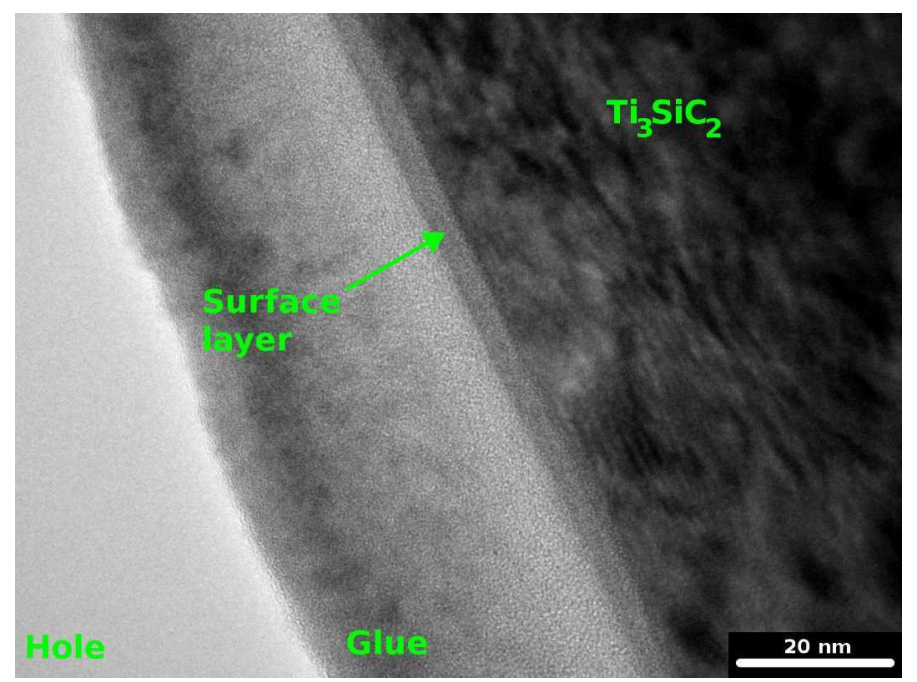

Figure 2: XTEM micrography of the surface of the pristine sample; $\mathrm{Ti}_{3} \mathrm{SiC}_{2}$ presents a native surface layer. 
This is confirmed by XPS results. Figure 3 shows both the Ti $2 p$ and Si $2 p$ XPS peaks of the pristine sample. In Figure $3 \mathrm{a}$, one can see the typical $\mathrm{Ti} 2 \mathrm{p}_{1 / 2}$ and $\mathrm{Ti} 2 \mathrm{p}_{3 / 2}$ peaks of the Ti-C bond of $\mathrm{Ti}_{3} \mathrm{SiC}_{2}$. Figure $3 \mathrm{~b}$ exhibits another typical peak of $\mathrm{Ti}_{3} \mathrm{SiC}_{2}$ around $99 \mathrm{eV}$. This peak has been already mentioned by Kisi et al., but not identified [26]. Lee et al. have also observed such a peak on a $\mathrm{TiSi}_{2}$ layer obtained by titanium ion bombardment on a silicon substrate [27]. They have attributed it to the formation of Ti-Si bond in the bombarded layer. Taking into account firstly that $\mathrm{Si}-\mathrm{C}$ bond does not exist in $\mathrm{Ti}_{3} \mathrm{SiC}_{2}$, and secondly that $\mathrm{Ti}-\mathrm{Si}$ bond length is close to the ideal covalent bond length [26], it seems likely that this peaks is related to $\mathrm{Ti}-\mathrm{Si}$ bond of $\mathrm{Ti}_{3} \mathrm{SiC}_{2}$.
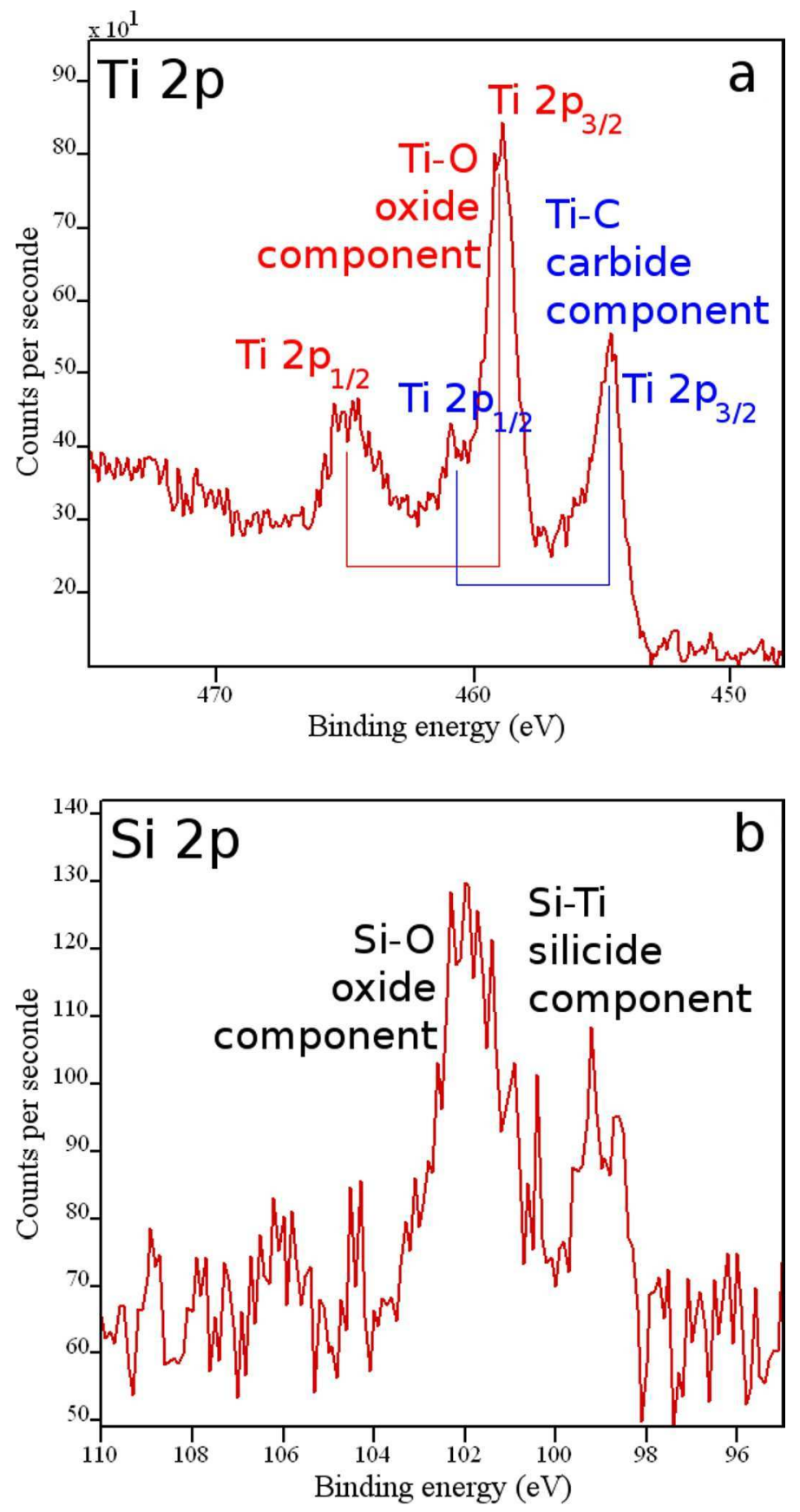

Figure 3: XPS spectra of the pristine sample: (a) Ti 2p peaks, and (b) Si 2p peaks.

Besides the characteristic peaks of $\mathrm{Ti}_{3} \mathrm{SiC}_{2}$, the XPS spectra highlight the presence of oxygen in the form of both titanium (Figure 3a) and silicon (Figure 3b) oxides, the two oxides that forms on $\mathrm{Ti}_{3} \mathrm{SiC}_{2}$ with temperature [28,29]. Thus, it appears that the thin layer laying down the surface of the pristine sample is a native oxide layer.

In the sample irradiated with $92 \mathrm{MeV}$ Xe ions to $10^{19} \mathrm{~m}^{-2}$, one can notice hills on surface by X-TEM (Figure 4). Observations under many inclinations indicate that the hills are amorphous (Figure 4b). The average thickness of this amorphous layer is bigger than for pristine sample, around $10 \mathrm{~nm}$. The roughness of the crystalline part of the sample 
does not show any noticeable change by comparison with the virgin one: hill formation occurs only in the amorphous layer on the surface.
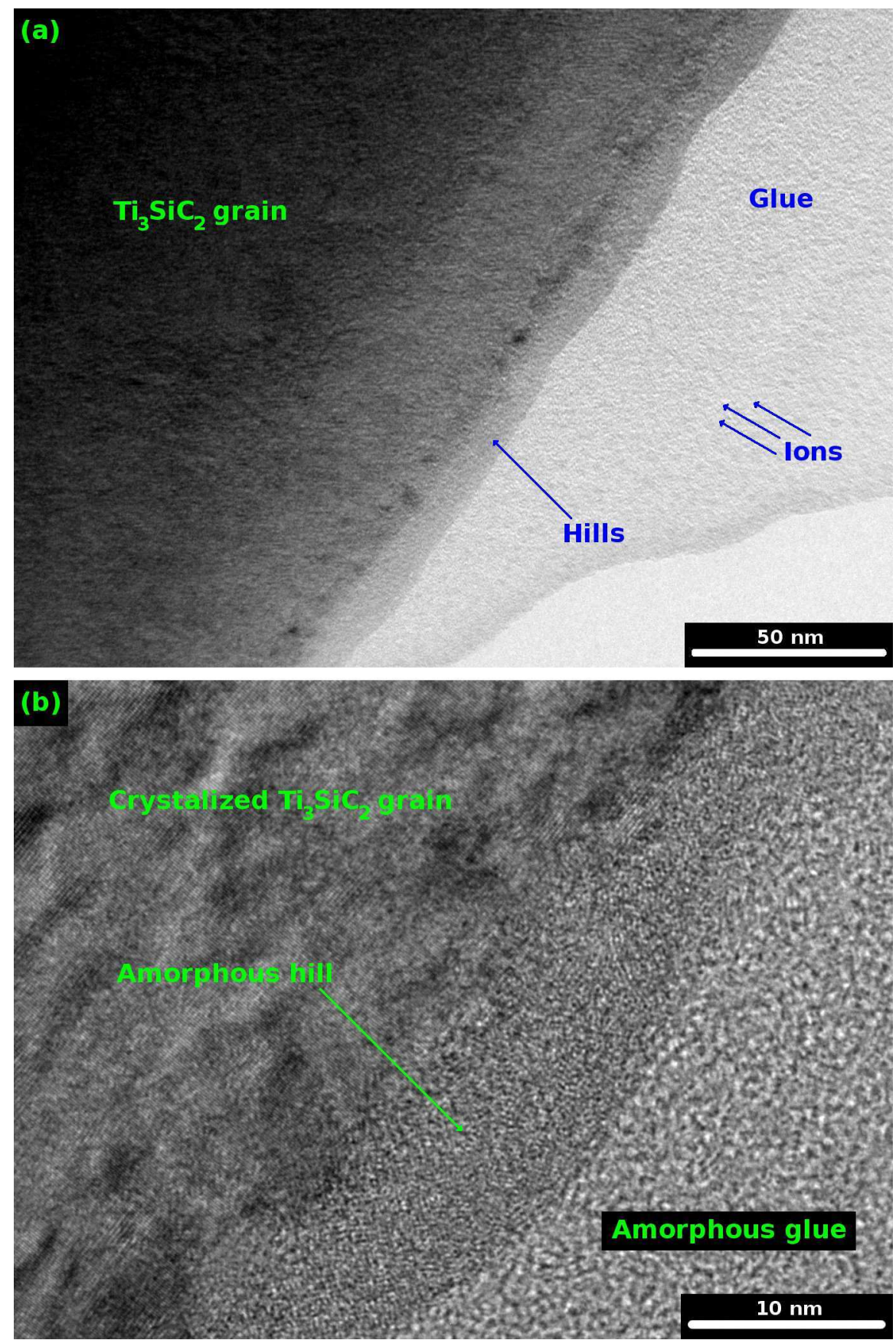

Figure 4: XTEM micrographs of the hills on sample irradiated with $92 \mathrm{MeV} \mathrm{Xe}$ ions to $10^{19} \mathrm{~m}^{-2}$; hills are amorphous.

Figure 5 shows XPS spectra after irradiation with $92 \mathrm{MeV}$ Xe ions to $10^{19} \mathrm{~m}^{-2}$. In these spectra, the peaks relative to $\mathrm{Ti}_{3} \mathrm{SiC}_{2}$ are not present anymore: only those of both titanium and silicon oxide can be noticed. 

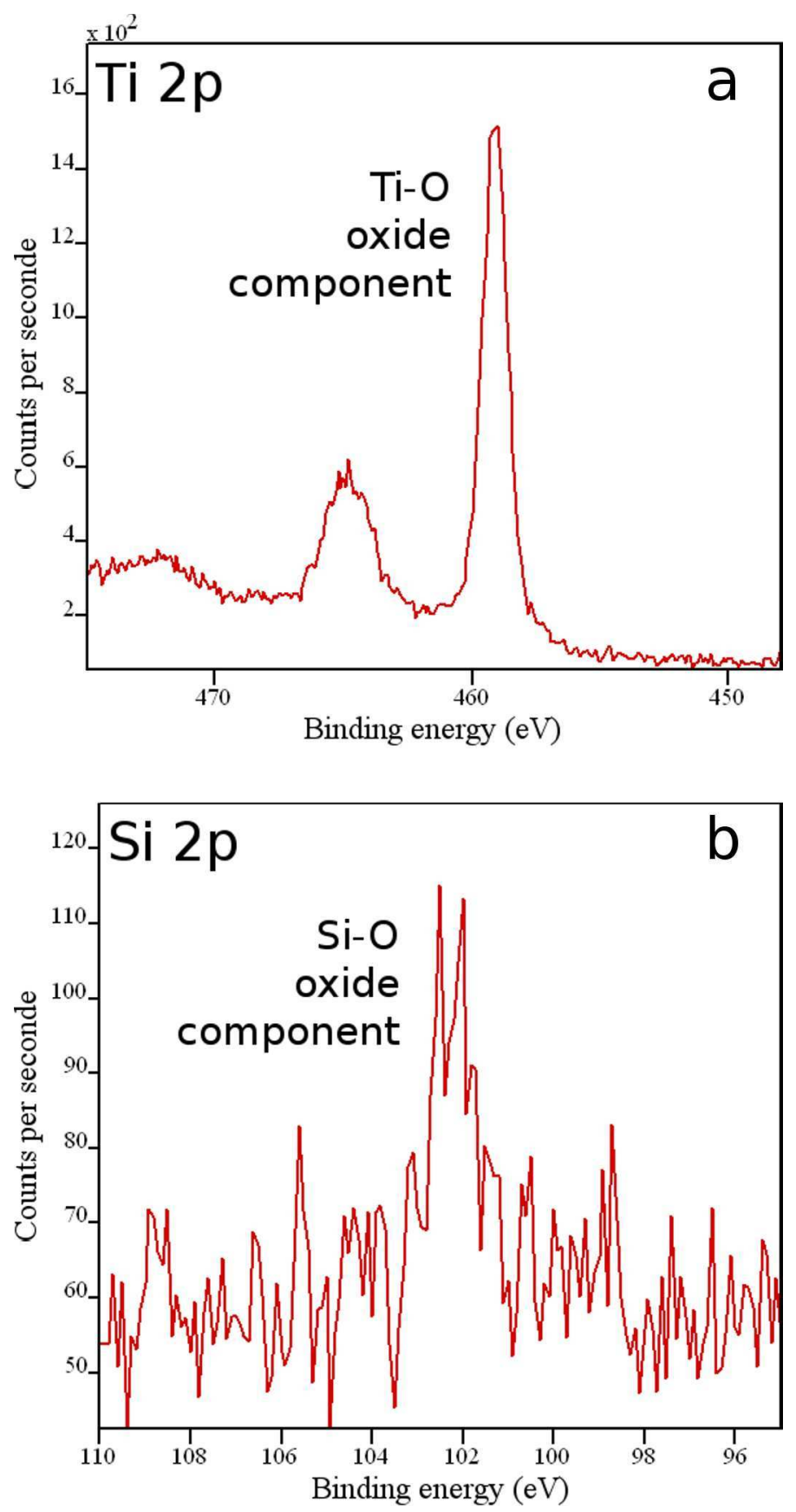

Figure 5: XPS spectra of the sample irradiated with $92 \mathrm{MeV} \mathrm{Xe}$ ions to $10^{19} \mathrm{~m}^{-2}$ : Ti $2 \mathrm{p}$ peaks, and (b) Si 2p peaks.

Hence, the hill formation on $\mathrm{Ti}_{3} \mathrm{SiC}_{2}$ samples is not occurring in this phase but in the native amorphous oxide layer on the surface, which grows during irradiation.

\subsection{Effect of ion fluence on the hill formation}

AFM observations indicate that the hill formation under $92 \mathrm{MeV}$ Xe ion irradiation starts between $2 \times 10^{18}$ and $4 \times 10^{18} \mathrm{~m}^{-}$ ${ }^{2}$, and that they grow in both diameter and height with the fluence (Figure 6). By performing many AFM profiles for each irradiated sample, we characterized both the diameter and the height of the hills, and evaluated their density (Table 2). 

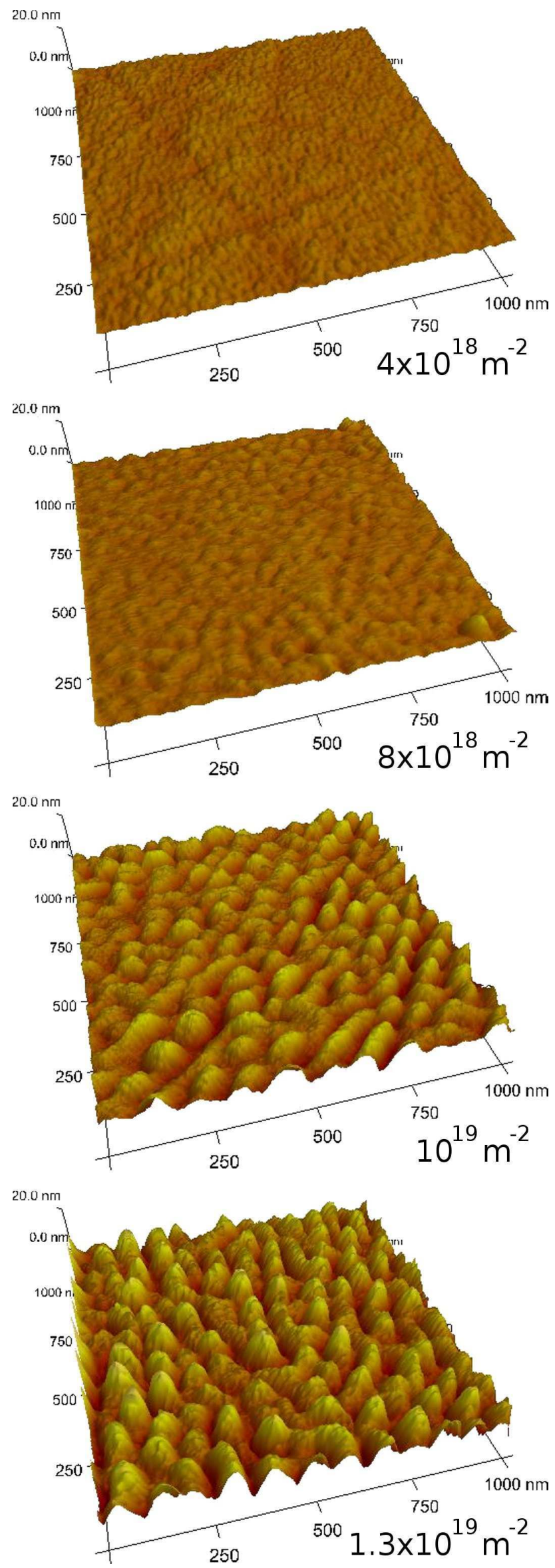

Figure 6: Evolution of the hill microstructure by AFM as a function of the fluence in $92 \mathrm{MeV} \mathrm{Xe}$ ions. 
The density of hills decreases with increasing the fluence up to reach saturation around $10^{19} \mathrm{~m}^{-2}$. At the beginning of the hill formation, their density is important and their height is small. For higher fluences, the hill diameter increases whereas the height stays constant, leading to a reduction of the hills density. When the density and the diameter saturate, the height of the hills grows.

Table 2: Description of the hill appearing on $\mathrm{Ti}_{3} \mathrm{SiC}_{2}$ as a function of the $92 \mathrm{MeV} \mathrm{Xe}$ ion fluence.

\begin{tabular}{lcccc}
\hline Fluence $\left(\mathrm{m}^{-2}\right)$ & Mean diameter $(\mathrm{nm})$ & Mean height $(\mathrm{nm})$ & Density $\left(\mu \mathrm{m}^{-2}\right)$ & Density $\left(\mathrm{m}^{-2}\right)$ \\
\hline $4 \times 10^{18}$ & $37.5 \pm 5.1$ & $2.06 \pm 0.28$ & $910 \pm 120$ & $(9.1 \pm 1.2) \times 10^{4}$ \\
$8 \times 10^{18}$ & $60.0 \pm 9.5$ & $2.26 \pm 0.47$ & $354 \pm 56$ & $(3.54 \pm 0.56) \times 10^{4}$ \\
$10^{19}$ & $97 \pm 14$ & $9.5 \pm 1.7$ & $136 \pm 20$ & $(1.36 \pm 0.20) \times 10^{4}$ \\
$1.3 \times 10^{19}$ & $98 \pm 12$ & $11.6 \pm 1.7$ & $133 \pm 16$ & $(1.33 \pm 0.16) \times 10^{4}$ \\
\hline
\end{tabular}

The proportion of oxides in the thickness analyzed by XPS was estimated by the ratio between the area of the Ti $2 \mathrm{p}_{3 / 2}$ peak relative to the Ti-O bond, and the sum of the areas of the two Ti $2 \mathrm{p}_{3 / 2}$ peaks (relative to both Ti-O and Ti-C bonds); by considering the Ti 2 p peak, the analyzed thickness is estimated to $5 \mathrm{~nm}$. Figure 7 shows the evolution of the oxide proportion in the first $5 \mathrm{~nm}$ as a function of the $92 \mathrm{MeV}$ Xe ion fluence.

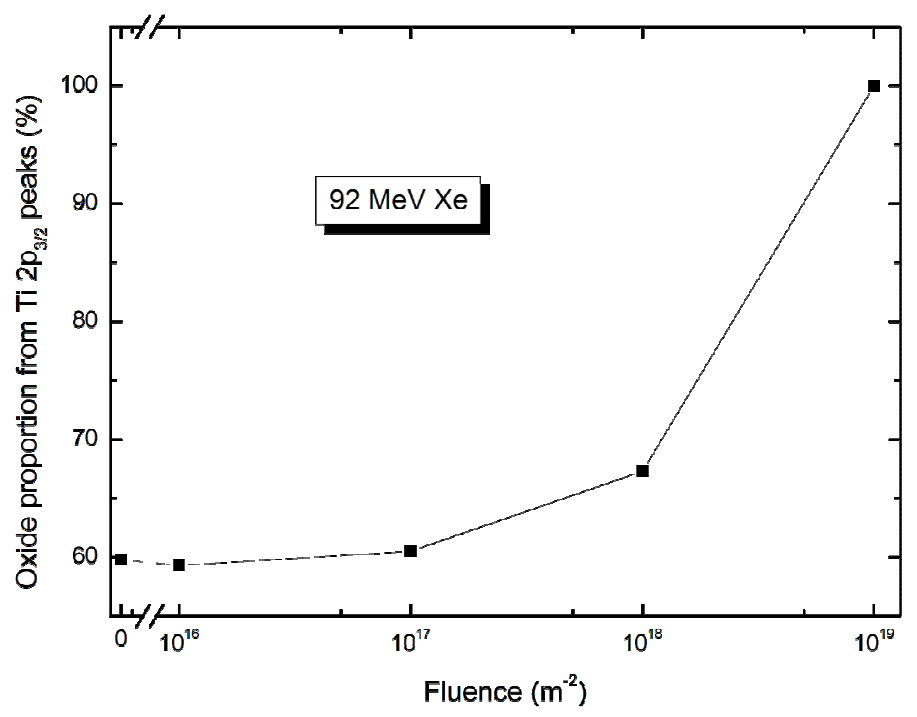

Figure 7: Evolution of the oxide proportion in the surface of samples irradiated with $92 \mathrm{MeV} \mathrm{Xe}$ ions as as a function of the fluence; the oxide proportion is estimated with the Ti $2 p_{3 / 2}$ XPS peaks.

The oxide thickness seems to be stable up to $10^{17} \mathrm{~m}^{-2}$, then slightly increases between $10^{17}$ and $10^{18} \mathrm{~m}^{-2}$ to reach $100 \%$ of the thickness analyzed by XPS to $10^{19} \mathrm{~m}^{-2}$ (Figure 7). Thus, it appears that the oxide layer grows before the formation of hills.

\subsection{Effect of the electronic and nuclear stopping powers on the hill formation}

Figure 8 shows the microstructure by AFM of samples irradiated with both $4 \mathrm{MeV}$ Au and $74 \mathrm{MeV} \mathrm{Kr}$ ions. No hill is evidenced by AFM for these two irradiation conditions. Note that the grain boundary revealing (Figure $8 \mathrm{a}$ ) is due to an anisotropic swelling induced by the nuclear collisions [30]. 

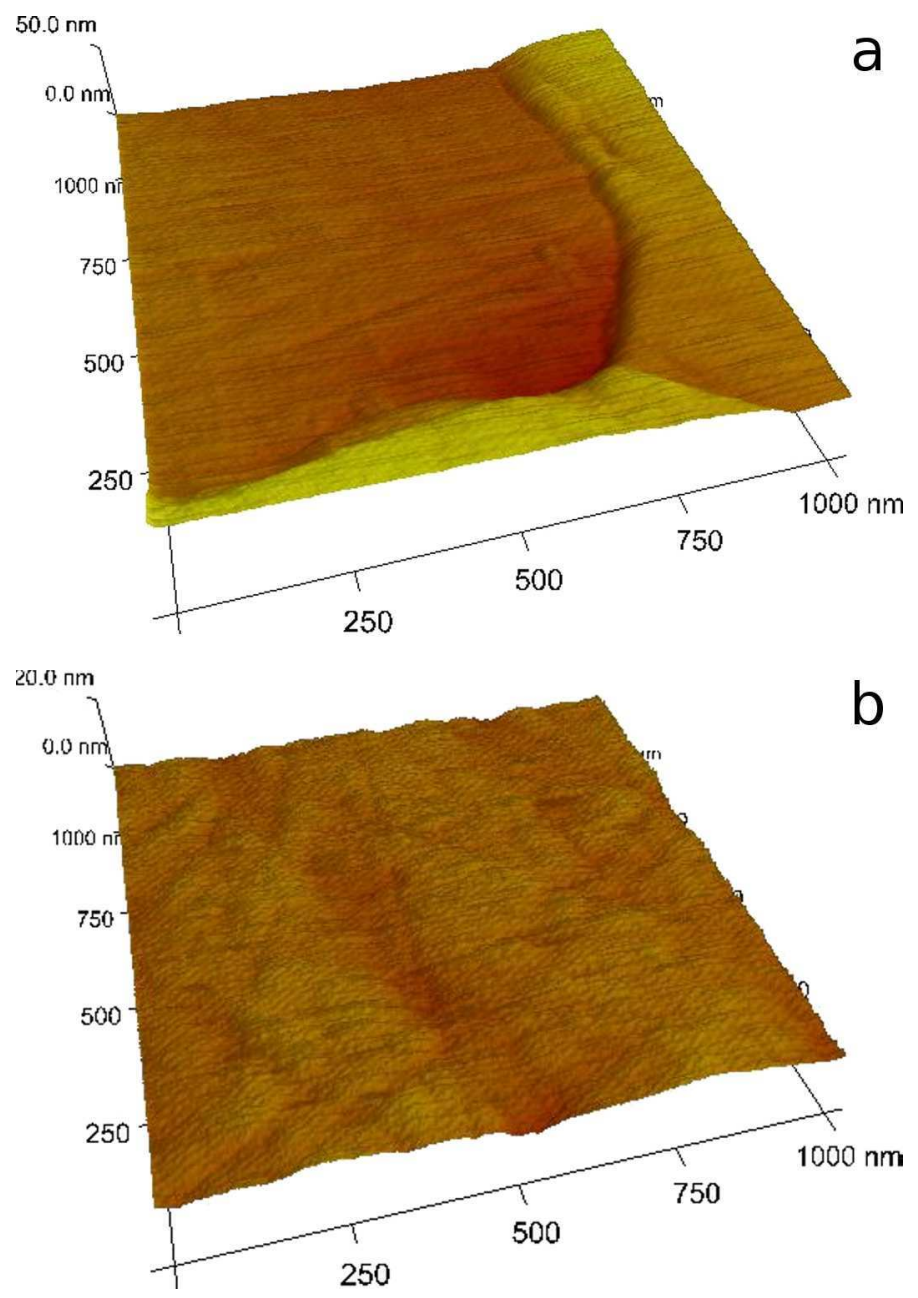

Figure 8: Microstructure of $\mathrm{Ti}_{3} \mathrm{SiC}_{2}$ grains by $\mathrm{AFM}$ for samples irradiated with (a) $4 \mathrm{MeV} \mathrm{Au}$ and (b) $74 \mathrm{MeV} \mathrm{Kr}$ ions to $10^{19} \mathrm{~m}^{-2}$; in Figure 8a the height scale is higher than for the other micrographs because of the nuclearinteraction induced anisotropic swelling that causes the revealing of the grains [30].

X-TEM micrographs of the surface of samples irradiated with both $4 \mathrm{MeV}$ Au and $74 \mathrm{MeV} \mathrm{Kr}$ ions to $10^{19} \mathrm{~m}^{-2}$ (Figure 9) confirm the absence of hills noticed by AFM (Figure 8). Moreover, if the oxide layer does not seem to be affected in the case of the sample irradiated with $4 \mathrm{MeV} \mathrm{Au}$ ions, its thickness appears to be larger for the $74 \mathrm{MeV} \mathrm{Kr}$ irradiation. This confirms that the oxide layer grows under electronic interactions, and that it could occur without hill formation. 

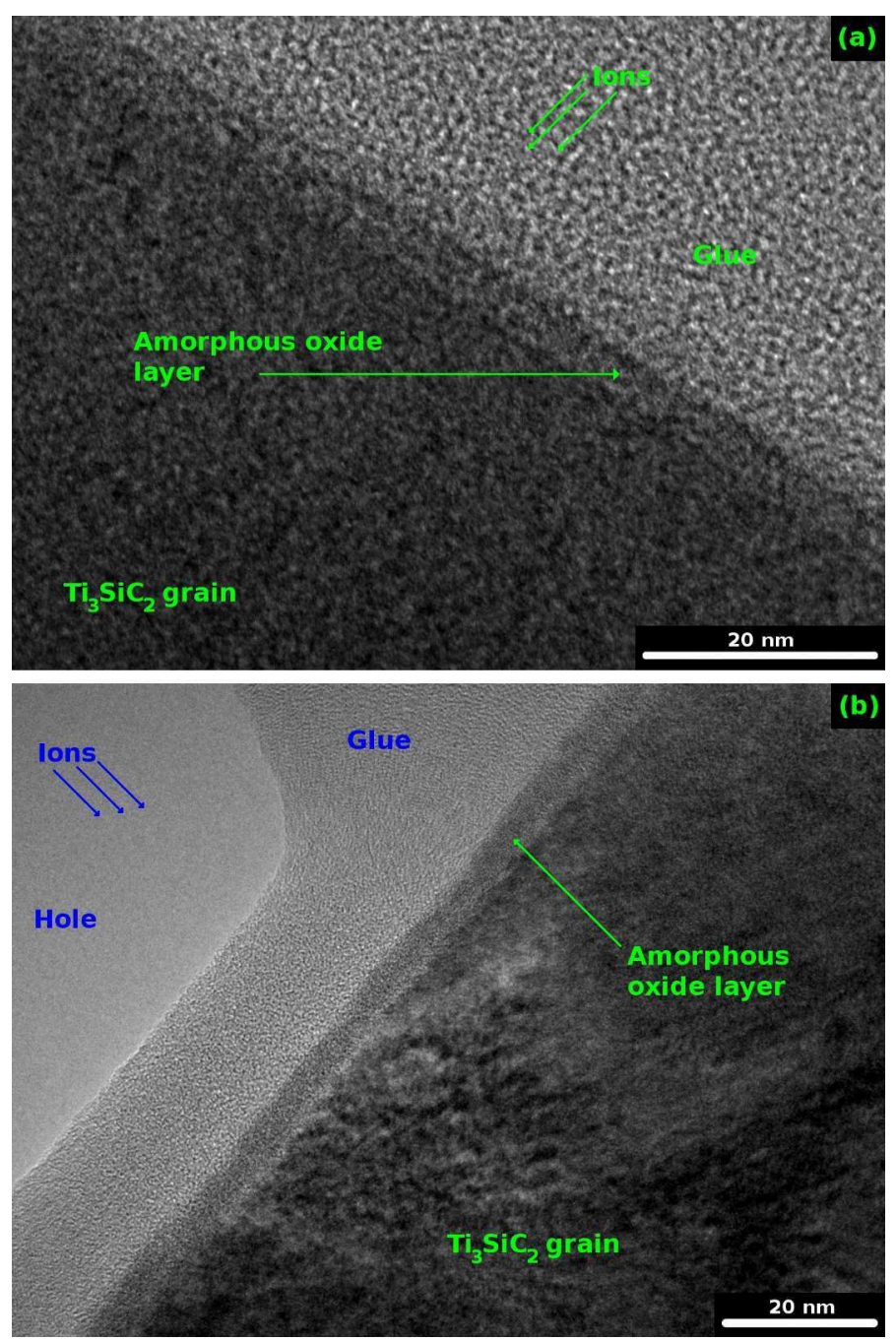

Figure 9: XTEM micrographs of the surface of samples irradiated with (a) $4 \mathrm{MeV}$ Au and (b) $74 \mathrm{MeV} \mathrm{Kr}$ ions to $10^{19} \mathrm{~m}^{-2}$.

We also evaluated this growth by the estimation of the oxide proportion by XPS: for the sample irradiated with $74 \mathrm{MeV}$ $\mathrm{Kr}$ to $10^{19} \mathrm{~m}^{-2}$, the peaks relative to $\mathrm{Ti}_{3} \mathrm{SiC}_{2}$ are always available. Figure 10 shows the evolution of the oxide proportion in the first $5 \mathrm{~nm}$ as a function of the electronic stopping power, for a fluence of $10^{19} \mathrm{~m}^{-2}$.

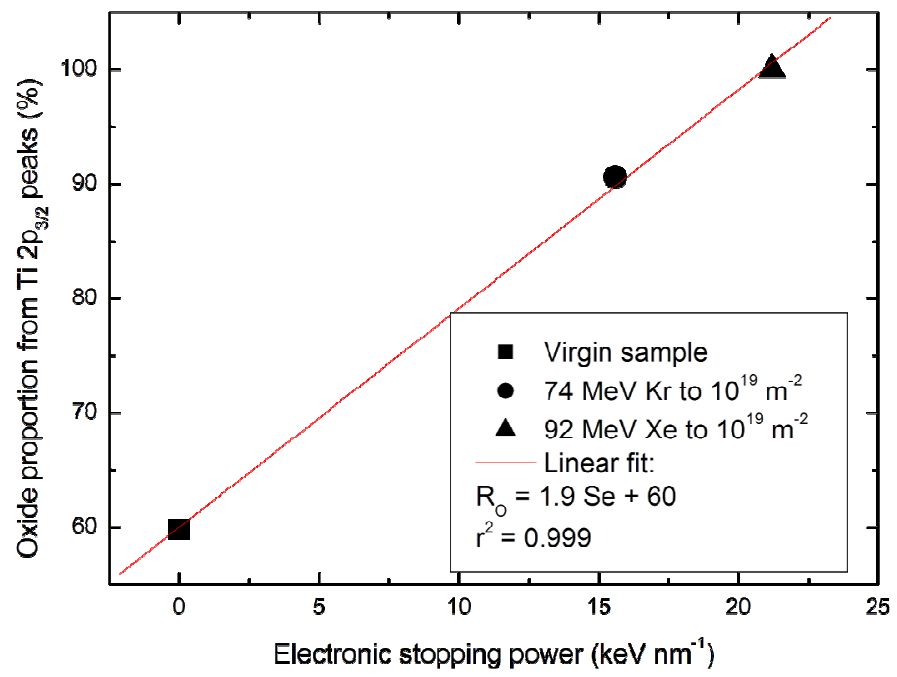

Figure 10: Evolution, as a function of the electronic stopping power, of the oxide proportion in the surface of samples irradiated to $10^{19} \mathrm{~m}^{-2}$; the oxide proportion is estimated with the Ti $2 \mathrm{p}_{3 / 2} \mathrm{XPS}$ peaks. 
Without paying much importance to the linear fit, which is achieved with only 3 points, it is interesting to note that a direct relationship seems to exist between the oxide layer thickness and the electronic stopping power. Hence, like the hill formation, the growth of the oxide layer seems to be induced by electronic interactions.

\section{Discussion}

The electronic interactions are known to cause various phenomena involving electrons, ions and atoms of the target. The result is usually a modification of the solid, which may be local or not [31]. All these phenomena are caused by energetic transfers from the ions to the atoms of the target. They usually occur beyond a certain threshold electronic stopping power $\mathrm{Se}_{\mathrm{th}}$, which corresponds to the energetic threshold of formation of ion tracks in the material [32,33]; this threshold mainly depends on the irradiated material.

The oxide layer thickness increases before the formation of hills. From our point of view, this increase may be caused either by its growth or by its swelling. In our case the thickness almost doubles, without any formation of cavities (Figure 9). Moreover, swift heavy ion irradiation leads to the compaction of amorphous materials in the direction parallel to the ion beam [34-36]. Therefore, we rather believe that the oxide layer thickness increase is due to its growth by oxidation of the underneath material. Such an oxidation has ever been observed on zirconium irradiated by fission products [37] or ions provided by the IRRSUD beamline [38,39] (more than $600 \mathrm{~nm}$ of oxide after $10^{19} \mathrm{~m}^{-2}$ but with higher residual pressure). Due to the large quantity of energy exchanged between the ions and the irradiated material, the electronic interactions usually increase the diffusion of species in the material. Thus, Avasthi et al. have shown that oxygen adsorbed on their iron films diffuses into the film when the electronic stopping power is higher than $\mathrm{Se}_{\mathrm{th}}$ of iron [40]. Since $\mathrm{Se}_{\mathrm{th}}$ would be around $6 \mathrm{keV} \mathrm{nm}^{-1}$ in titanium oxide [41], and less than $4 \mathrm{keV} \mathrm{nm}^{-1}$ in amorphous silicon oxide [42], the increase of the oxide layer thickness could be the result of the oxidation of $\mathrm{Ti}_{3} \mathrm{SiC}_{2}$ by the residual oxygen in the irradiation chamber (pressure between $10^{-4}$ and $10^{-5} \mathrm{~Pa}$ ). Based first on the works led by Roller et al. [43], and second on the structural damage induced by heavy ion irradiation in $\mathrm{Ti}_{3} \mathrm{SiC}_{2}$, which indicates that $\mathrm{Se}_{\text {th }}$ of $\mathrm{Ti}_{3} \mathrm{SiC}_{2}$ is above $28 \mathrm{keV} \mathrm{nm}^{-1}[19,44]$, we suggest the following oxidation mechanism. It seems indeed likely that the electronic interactions induce the diffusion of adsorbed oxygen inside the oxide layer toward the $\mathrm{Ti}_{3} \mathrm{SiC}_{2} /$ oxide interface, which would be the reactive front where the oxidation occurs.

As previously suggested [22], the fact that $4 \mathrm{MeV}$ Au ion irradiation induces no hill formation indicates that this phenomenon is due to electronic interactions and not to ballistic collisions. Concerning the $74 \mathrm{MeV} \mathrm{Kr}$ irradiation, the electronic stopping power seems to be too low for the hill formation: therefore, this phenomenon would occur either above a threshold Se, or above a critical fluence that would decrease when Se increases. This electronic energy loss threshold (15.7 $\mathrm{keV} \mathrm{nm}^{-1}$ in $\mathrm{Ti}_{3} \mathrm{SiC}_{2}$ for $74 \mathrm{MeV} \mathrm{Kr}$ ) is high by comparison to electronic energy loss threshold for track formation in the oxide layer.

In the literature, many authors have also observed hills on other materials irradiated by SHI due to electronic interactions $[45,46]$, but in these cases each so-called "hillock" was created by the passage of one single ion. In our samples, in the single impact regime (fluence lower than $10^{16} \mathrm{~m}^{-2}$ ) no hills were observed. At fluence for which hills are observed, the calculated hill density is well below the fluence and decreases when increasing fluence (Table 2). Therefore, the hill formation is not the result of a single ion. Previous results indicates that $\mathrm{Ti}_{3} \mathrm{SiC}_{2}$ is insensitive to electronic interaction [44]. In this work, TEM observation indicates that the hill formation occurs in the oxide layer on the surface of $\mathrm{Ti}_{3} \mathrm{SiC}_{2}$, but not in the MAX phases, confirming that the electronic energy loss of $92 \mathrm{MeV} \mathrm{Xe}$ ions $\left(21.5 \mathrm{keV} \mathrm{nm}^{-1}\right)$ is not sufficient to induce modification in $\mathrm{Ti}_{3} \mathrm{SiC}_{2}$. So we could conclude that the observed phenomenon is due to electronic interaction in the oxide layer and need ion tracks recovery.

As far as we know, the formation of hills by several SHI, in irradiation conditions similar to those of this study, has never been observed on other materials [22]. However, note that similar relief, so-called ripples, can be observed on samples irradiated with ions of lower energy (few hundred of $\mathrm{keV}$ ) to higher fluences (above $10^{20} \mathrm{~m}^{-2}$ ) [47-49]. Nevertheless, this phenomenon differs from that observed in this study, first because of the irradiation conditions, and second because ripples are usually observed as well in the amorphous layer as in the crystalline structure under the amorphous layer $[47,48]$.

In amorphous silicon irradiated with SHI above $\mathrm{Se}_{\mathrm{th}}$ to $10^{19} \mathrm{~m}^{-2}$, Hedler et al. have shown a plastic deformation that they have attributed to the ion hammering effect [50], also called Klaumünzer effect [51,52]. The model relative to this effect predicts an anisotropic growth of amorphous phase irradiated by SHI, to wit both an expansion perpendicular and a shrinkage parallel to the ion beam direction. The characteristics of this anisotropic growth are the followings [51]:

- Beyond a certain incubation fluence $\phi_{c}$, the dimensional changes increase with the fluence;

- $\phi_{\mathrm{c}}$ decreases when Se increases [53];

- The deformation rate is low at low $\mathrm{Se}$, and increases linearly beyond $\mathrm{Se}_{\mathrm{th}}$; 
- The dimensional changes decrease with increasing temperature.

Trinkaus have shown that this phenomenon stems from the effect of the thermal stresses induced by the electronic interactions [51]. In the region around the ion track, these interactions allow a relaxation of the stresses. Nevertheless, according to the thermal spike model [32,33], the sudden cooling of this relaxed state induces a track highly constrained, which represents a mesoscopic defect responsible for the growth of the affected area, perpendicularly to the ion beam.

This effect seems to occur in all the amorphous materials, including metals, ceramics and polymers [34-36]. Thus, following this model, a hypothesis concerning the hill formation would be that ion hammering effect in the oxide layer induces strong stresses, which are opposed to the growth of this layer. Theses stresses could then, in a mechanism not understood yet, be accommodated by the formation of hills on the surface. This accommodation would hence take place beyond an incubation fluence $\phi_{\mathrm{c}}$ that decreases when increasing Se. For irradiations with $74 \mathrm{MeV} \mathrm{Kr}$ ions, there are two possibilities: either $\mathrm{Se}$ is smaller than $\mathrm{Se}_{\mathrm{th}}$, or $\phi_{\mathrm{c}}$ is higher than $10^{19} \mathrm{~m}^{-2}$.

\section{Conclusion}

In this work, we studied both the composition and the formation of hills induced by swift heavy ion (SHI) irradiation of $\mathrm{Ti}_{3} \mathrm{SiC}_{2}$ samples. We first showed that before irradiation the surface of the samples is coated with an amorphous oxide layer with both titanium and silicon. The thickness of this layer increases with the SHI fluence and the growth rate seems to increase with the electronic stopping power. We attributed this to the oxidation of $\mathrm{Ti}_{3} \mathrm{SiC}_{2}$ : $\mathrm{SHI}$ would enhance the diffusion of adsorbed oxygen atoms through the oxide layer, and the oxidation would occur at the $\mathrm{Ti}_{3} \mathrm{SiC}_{2} / \mathrm{oxide}$ interface, leading to an increase of the oxide thickness.

We also showed that the formation and the growth of the hills depend on both the fluence and the electronic stopping power. Based on the Klaumünzer effect model, we consider that the hills are formed on the surface to accommodate high stresses in the oxide layer. Thus, the hills would be formed only for electronic stopping power higher than a threshold $\mathrm{Se}_{\mathrm{th}}$, and beyond a certain incubation fluence $\phi_{\mathrm{c}}$, which would decrease when the electronic stopping power increases. This hypothesis is in agreement with the overall results obtained in this study.

These results clearly evidence that the hill formation previously observed on the surface of irradiated $\mathrm{Ti}_{3} \mathrm{SiC}_{2}$ is not the sign of a modification of the MAX phase under swift heavy ion irradiation, but is due to an irradiation effect on the amorphous layer on top.

\section{Acknowledgements}

The authors would like to gratefully thank on the one hand Pierre Passet and Vincent Barnier of the SMS center of the École Nationale Supérieure des Mines (Saint-Étienne, France) for their help during XPS analyzes, and on the other hand Lionel Thomé of the CSNSM (Orsay, France) for his help during irradiation experiments. They acknowledge financial supports from both the French CNRS and CEA METSA network, and the French research group MATINEX.

\section{References}

[1] US.DoE, <http://nuclear.energy.gov/genIV/neGenIV1.html>.

[2] Y. Katoh, L.L. Snead, T. Nozawa, T. Hinoki, A. Kohyama, N. Igawa, T. Taguchi, Mechanical properties of chemically vapor-infiltrated silicon carbide structural composites with thin carbon interphases for fusion and advanced fission applications, Mater. Trans. 46 (2005) 527-535.

[3] L.L. Snead, Y. Katoh, W.E. Windes, R.J. Shinavski, T.D. Burchell, Ceramic composites for near term reactor application, Proceedings of the 4th International Topical Meeting on High Temperature Reactor Technology, 2, Washington, D.C., USA, (2008) 1-10.

[4] J. Cabrero, F. Audubert, R. Pailler, A. Kusiak, J.L. Battaglia, P. Weisbecker, Thermal conductivity of SiC after heavy ions irradiation, J. Nucl. Mater. 396 (2010) 202-207.

[5] L.L. Snead, S.J. Zinkle, J.C. Hay, M.C. Osborne, Amorphization of SiC under ion and neutron irradiation, Nucl. Instrum. Methods Phys. Res. Sect. B: Beam Interact. Mater. Atoms 141 (1998) 123-132.

[6] D. Gosset, D. Simeone, D. Quirion, Neutron irradiation damage to boron carbide: X-ray diffraction analysis, J. Phys. IV 10 (2000) Pr10-55-63.

[7] A. Benyagoub, A. Audren, L. Thome, F. Garrido, Athermal crystallization induced by electronic excitations in ion-irradiated silicon carbide, Appl. Phys. Lett. 89 (2006) 241914.

[8] D. Gosset, M. Dollé, D. Simeone, G. Baldinozzi, L. Thomé, Structural evolution of zirconium carbide under ion irradiation, J. Nucl. Mater. 373 (2008) 123-129. 
[9] M.W. Barsoum, The M(n+1)AX(n) phases: A new class of solids; Thermodynamically stable nanolaminates, Prog. Solid State Chem. 28 (2000) 201-281.

[10] M.W. Barsoum, T. El-Raghy, The MAX phases: Unique new carbide and nitride materials - Ternary ceramics turn out to be surprisingly soft and machinable, yet also heat-tolerant, strong and lightweight, Am. Scientist 89 (2001) 334-343.

[11] R. Radhakrishnan, J. J. Williams, M. Akinc, Synthesis and high-temperature stability of Ti3SiC2, J. Alloy. Compd. 285 (1999) 85-88.

[12] J.J. Nickl, K.K. Schweitzer, P. Luxenberg, Gasphasenabscheidung im Systeme Ti-C-Si, J. Less-Common Metals 26 (1972) 335-353.

[13] T. Goto, T. Hirai, Chemically vapor-deposited Ti3SiC2, Mater. Res. Bull. 22 (1987) 1195-1201.

[14] R. Pampuch, J. Lis, L. Stobierski, M. Tymkiewicz, Solid Combustion Synthesis of Ti3SiC2, J. Eur. Ceram. Soc. 5 (1989) 283-287.

[15] C.J. Gilbert, D.R. Bloyer, M.W. Barsoum, T. El-Raghy, A.P. Tomsia, R.O. Ritchie, Fatigue-crack growth and fracture properties of coarse and fine-grained Ti3SiC2, Scr. Mater. 42 (2000) 761-767.

[16] M.W. Barsoum, T. El-Raghy, Synthesis and characterization of a remarkable ceramic: Ti3SiC2, J. Am. Ceram. Soc. 79 (1996) 1953-1956.

[17] M.W. Barsoum, T. El-Raghy, C.J. Rawn, W.D. Porter, H. Wang, E.A. Payzant, C.R. Hubbard, Thermal properties of Ti3SiC2, J. Phys. Chem. Solids 60 (1999) 429-439.

[18] J.C. Nappé, Ph. Grosseau, B. Guilhot, F. Audubert, M. Beauvy, M. Benabdesselam, Heavy ions induced damages in Ti3SiC2: Effect of irradiation temperature, Mechanical Properties and Performance of Engineering Ceramics and Composites IV, 30, Hoboken, NJ, USA, D. Singh \& W.M. Kriven (2010) 199-204.

[19] M. Le Flem, X. Liu, S. Doriot, T. Cozzika, I. Monnet, Irradiation damage in Ti3(Si,Al)C2: a TEM investigation, Int. J. Appl. Ceram. Technol. 7 (2010) 766-775.

[20] X. Liu, M. Le Flem, J.L. Béchade, I. Monnet, Nanoindentation investigation of heavy ion irradiated Ti3(Si,Al)C2, J. Nucl. Mater. 401 (2010) 149-153.

[21] X. Liu, M. Le Flem, J.L. Béchade, F. Onimus, T. Cozzika, I. Monnet, XRD investigation of ion irradiated Ti3Si0.90A10.10C2, Nucl. Instrum. Methods Phys. Res. Sect. B: Beam Interact. Mater. Atoms 268 (2010) 506-512.

[22] J.C. Nappé, Ph. Grosseau, F. Audubert, B. Guilhot, M. Beauvy, M. Benabdesselam, I. Monnet, Damages induced by heavy ions in titanium silicon carbide: Effects of nuclear and electronic interactions at room temperature, J. Nucl. Mater. 385 (2009) 304-307.

[23] J.F. Ziegler, <http://www.srim.org/>.

[24] <http://www.casaxps.com/>.

[25] D.A. Shirley, High-resolution X-ray photoemission spectrum of valence bands of gold, Phys. Rev. B 5 (1972) 4709-4714.

[26] E.H. Kisi, J.A.A. Crossley, S. Myhra, M.W. Barsoum, Structure and crystal chemistry of Ti3SiC2, J. Phys. Chem. Solids 59 (1998) 1437-1443.

[27] S.M. Lee, E.T. Ada, H. Lee, J. Kulik, J.W. Rabalais, Growth of Ti and TiSi2 films on Si(111) by low energy Ti+ beam deposition, Surf. Sci. 453 (2000) 159-170.

[28] N.F. Gao, Y. Miyamoto, D. Zhang, On physical and thermochemical properties of high-purity Ti3SiC2, Mater. Lett. 55 (2002) 61-66.

[29] M.W. Barsoum, T. El-Raghy, L. Ogbuji, Oxidation of Ti3SiC2 in air, J. Electrochem. Soc. 144 (1997) 25082516.

[30] J.C. Nappé, C. Maurice, Ph. Grosseau, F. Audubert, L. Thome, B. Guilhot, M. Beauvy, M. Benabdesselam, Microstructural changes induced by low energy heavy ion irradiation in titanium silicon carbide, Journal of the European Ceramic Society (In press).

[31] W.M. Arnoldbik, N. Tomozeiu, F.H.P.M. Habraken, Electronic sputtering of thin SiO2 films by MeV heavy ions, Nucl. Instrum. Methods Phys. Res. Sect. B: Beam Interact. Mater. Atoms 203 (2003) 151-157. 
[32] M. Toulemonde, C. Dufour, E. Paumier, Transient thermal-process after a high-energy heavy-ion irradiation of amorphous metals and semiconductors, Phys. Rev. B 46 (1992) 14362-14369.

[33] M. Toulemonde, E. Paumier, C. Dufour, Thermal spike model in the electronic stopping power regime, Radiat. Eff. Defects Solids 126 (1993) 201-206.

[34] S. Klaumünzer, G. Schumacher, Dramatic growth of glassy Pd80Si20 during heavy-ion irradiation, Phys. Rev. Lett. 51 (1983) 1987-1990.

[35] S. Klaumünzer, Ion-beam-induced plastic-deformation: a universal phenomenon in glasses, Radiat. Eff. Defects Solids 110 (1989) 79-83.

[36] S. Klaumünzer, Plastic-deformation of amorphous solids by track overlap, Int. J. Radiat. Appl.Instrum. Part D: Nucl. Tracks Radiat. Meas. 19 (1991) 91-96.

[37] N. Bérerd, H. Catalette, A. Chevarier, N. Chevarier, H. Faust, N. Moncoffre, Zirconium surface modification under fission product irradiation. Application to nuclear fuel cladding tubes, Surf. Coat. Technol. 158-159 (2002) 473476.

[38] N. Bérerd, A. Chevarier, N. Moncoffre, H. Jaffrézic, E. Balanzat, H. Catalette, Zirconium oxidation under high energy heavy ion irradiation, J. Appl. Phys. 97 (2005) 083528.

[39] N. Bérerd, N. Moncoffre, A. Chevarier, H. Jaffrézic, H. Faust, E. Balanzat, Study of the zirconium oxidation under heavy ion irradiation, Nucl. Instrum. Methods Phys. Res. Sect. B: Beam Interact. Mater. Atoms 249 (2006) 513516.

[40] D.K. Avasthi, W. Assmann, A. Tripathi, S.K. Srivastava, S. Ghosh, F. Grüner, M. Toulemonde, Transient enhanced diffusion of oxygen in Fe mediated by large electronic excitation, Phys. Rev. B 68 (2003) 153106.

[41] K. Nomura, T. Nakanishi, Y. Nagasawa, Y. Ohki, K. Awazu, M. Fujimaki, N. Kobayashi, S. Ishii, K. Shima, Structural change induced in $\mathrm{TiO} 2$ by swift heavy ions and its application to three-dimensional lithography, Phys. Rev. B 68 (2003) 064106.

[42] J. Jensen, A. Razpet, M. Skupinski, G. Possnert, Ion track formation below $1 \mathrm{MeV} / \mathrm{u}$ in thin films of amorphous SiO2, Nucl. Instrum. Methods Phys. Res. Sect. B: Beam Interact. Mater. Atoms 243 (2006) 119-126.

[43] T. Roller, W. Bolse, Oxygen diffusion and oxide phase formation in iron under swift heavy ion irradiation, Phys. Rev. B 75 (2007) 054107.

[44] J.C. Nappé, I. Monnet, Ph. Grosseau, F. Audubert, B. Guilhot, M. Beauvy, L. Thomé, M. Benabdesselam, Structural changes induced by heavy ion irradiation in titanium silicon carbide, J. Nucl. Mater. 409 (2011) 53-61.

[45] V.A. Skuratov, A.E. Efimov, K. Havancsak, Surface modification of MgAl2O4 and oxides with heavy ions of fission fragments energy, Nucl. Instrum. Methods Phys. Res. Sect. B: Beam Interact. Mater. Atoms 250 (2006) $245-249$.

[46] S. Moll, L. Thome, L. Vincent, F. Garrido, G. Sattonnay, T. Thome, J. Jagielski, J.M. Costantini, Damage induced by electronic excitation in ion-irradiated yttria-stabilized zirconia, J. Appl. Phys. 105 (2009) 023512.

[47] T.K. Chini, F. Okuyama, M. Tanemura, K. Nordlund, Structural investigation of keV Ar-ion-induced surface ripples in Si by cross-sectional transmission electron microscopy, Physical Review B 67 (2003) 205403.

[48] T.K. Chini, D.P. Datta, U. Luchhesi, A. Mücklich, Photoluminescence from Si: Effect of ripple microstructures induced by argon ion irradiation, Surf. Coat. Technol. 203 (2009) 2690-2693.

[49] S. Rusponi, G. Costantini, C. Boragno, U. Valbusa, Ripple wave vector rotation in anisotropic crystal sputtering, Phys. Rev. Lett. 81 (1998) 2735-2738.

[50] A. Hedler, S. Klaumünzer, W. Wesch, Swift heavy ion irradiation of amorphous silicon, Nucl. Instrum. Methods Phys. Res. Sect. B: Beam Interact. Mater. Atoms 242 (2006) 85-87.

[51] H. Trinkaus, Dynamics of viscoelastic flow in ion tracks: origin of plastic deformation of amorphous materials, Nucl. Instrum. Methods Phys. Res. Sect. B: Beam Interact. Mater. Atoms 146 (1998) 204-216.

[52] H. Trinkaus, A.I. Ryazanov, Viscoelastic model for the plastic-flow of amorphous solids under energetic ionbombardment, Phys. Rev. Lett. 74 (1995) 5072-5075.

[53] A. Audouard, E. Balanzat, J.C. Jousset, D. Lesueur, L. Thome, Atomic displacements and atomic motion induced by electronic excitation in heavy-ion-irradiated amorphous metallic alloys, J. Phys.: Condens. Matter 5 (1993) 9951018 . 
